\title{
Rancang Bangun Wireless Sensor Network Peringatan Dini Longsor Berbasis Mikrokontroler
}

\author{
Denny Nugroho ${ }^{1}$, Uswarman $^{2}$ \\ Program Studi Teknik Elektro Institut Teknologi Sumatera, Lampung Selatan \\ ${ }^{1}$ denny. nugrohodel.itera.ac.id \\ 2uswarmandel.itera.ac.id
}

Intisari - Bencana alam seperti gerakan tanah atau longsor dapat terjadi pada berbagai skala dan kecepatan. Untuk meminimalkan kerugian akibat bencana tersebut maka dilakukan usaha mengenal tandatanda yang mengawali gerakan tanah, atau disebut sebagai mitigasi. Penelitian ini dilakukan untuk merancang wireless sensor network yang mampu mengidentifikasi bencana longsor. Node sensor terdiri dari: sensor getaran, sensor kemiringan lahan, sensor pergeseran lahan, kontroler, dan modul transmisi data. Node-node sensor ini ditanam pada daerah yang rawan longsor dan saling berkomunikasi antara node satu dengan lainnya. Data-data berupa getaran, kemiringan lahan, dan status selalu ditransmisikan ke base station sistem peringatan dini longsor secara realtime. Ketika bencana longsor akan segera terjadi node sensor diharapkan mampu mendeteksi dan mengaktifkan alarm yang ada pada node sensor serta mengirimkan tanda bahaya ke base station.

Kata Kunci — longsor, wireless sensor network, node sensor, mikrokontroler

Abstrak - Natural disasters such as land movements or landslides can occur at various scales and speeds. To minimize damages due to the disaster, an effort is made to recognize the signs that initiate soil movements or referred to as mitigation. This research was conducted to design a wireless sensor network that can identify landslides. Sensor nodes consist of vibration sensor, slope sensor, land shift sensor, controller, and data transmission module. These sensor nodes are planted in areas inclined to landslides and communicate with each other between nodes. The data vibration, the slope of the land, and status are always transmitted to the base station of the landslide early warning system in real time. When an landslide will occur soon the sensor node is expected to be able to detect and activate the alarm on the sensor node and send an signal to the base station.

Keyword — landslides, wireless sensor networks, sensor nodes, microcontrollers

\section{PENDAHULUAN}

Longsor adalah gerakan massa batuan atau tanah pada suatu lereng karena pengaruh gaya gravitasi. Gerakan massa batuan atau tanah terjadi karena adanya gangguan terhadap keseimbangan gaya penahan (shear strength) dan gaya peluncur (shear stress) yang bekerja pada suatu lereng. Ketidakseimbangan gaya tersebut diakibatkan adanya gaya dari luar lereng yang menyebabkan besarnya gaya peluncur pada suatu lereng menjadi lebih besar daripada gaya penahannya Dibanding bahaya geologi lainnya (gempa bumi, tsunami atau letusan gunung api), setiap tahunnya gerakan tanah lebih sering terjadi di wilayah perbukitan di Indonesia. Menurut data dan informasi bencana di Indonesia (DIBI-BNPB), kejadian bencana gerakan tanah di Indonesia selama 10 tahun (2004- 2013) mencapai 1.990 peristiwa, dengan kejadian terbanyak pada 2010 yang mencapai 400 kejadian [3]. Provinsi Lampung memiliki daerah rawan longsor tinggi tersebar pada 9 kabupaten/kota dengan luas mencapai $621 \mathrm{~km}^{2}$. Dari luas wilayah tersebut Kabupaten Lampung Barat memiliki wilayah terluas 192,05 km², Kabupaten Tanggamus 168,07 $\mathrm{km}^{2}$ dan Kabupaten Lampung Selatan 128,44 $\mathrm{km}^{2}$. Kabupaten Lampung Barat dan Tanggamus yang sebagian besar wilayahnya merupakan bukit dan perbukitan dengan kemiringan lereng > $45 \%$ serta terdapat zona sesar aktif Sumatera dan curah hujan yang tinggi, akan semakin meningkat kejadian longsornya bila intervensi manusia pada lereng juga semakin meningkat [4]. 


\section{TINJAUANA PUSTAKA}

\section{A. Pergeseran Tanah}

Bencana alam seperti gerakan tanah, terutama longsor, dapat terjadi pada berbagai skala dan kecepatan. Di alam, banjir dan longsor sering terjadi hampir bersamaan dan disebabkan oleh hujan yang sangat lebat yang di dalam gerakan tanah disebut sebagai unsur pemicu. Untuk meminimalkan kerugian akibat bencana tersebut maka dilakukan usaha mengenal tanda-tanda yang mengawali gerakan tanah, atau disebut sebagai mitigasi. Lereng sebagai salah satu kenampakan penting di dalam bentang alam, di dalam waktu yang panjang akan berevolusi dan material permukaan pada lereng akan bergerak turun karena gaya gravitasi. Faktor-faktor dinamik proses pembentukan bentang alam dapat dibedakan menjadi faktor pasif dan faktor aktif (gambar 1). Faktor pasif berkaitan erat dengan keadaan lapisan bawah permukaan dan produknya di bagian permukaan. Hal ini sangat dipengaruhi oleh jenis litologi (batuan), kemiringan perlapisannya (perlapisan tegak, miring ataupun mendatar), strukturnya (banyak terdapat rekahan), dan posisinya di dalam bentang alam (pada lembah, tebing ataupun puncak).Faktor aktif berkaitan erat dengan agen erosi, yaitu: gaya gravitasi, iklim, tektonika aktif, dan perubahan sudut kelerengan, serta proses biologi.

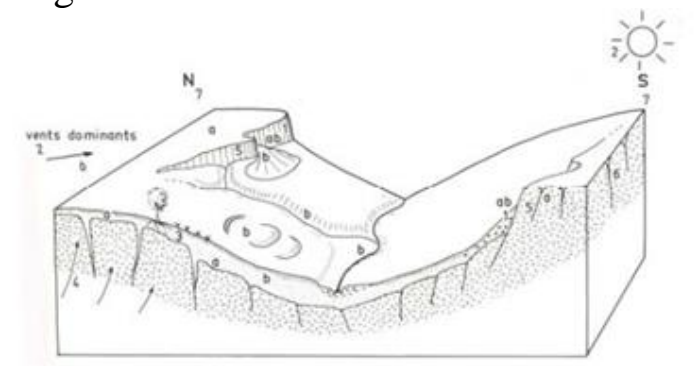

Gbr.1 Dinamika Proses Permukaan Bumi

Akibat kombinasi unsur-unsur di kedua faktor tersebut, batuan akan mengalami degradasi menjadi tanah. Peristiwa ini biasa disebut sebagai pelapukan (weathering). Pelapukan dapat berlangsung secara fisis maupun kimiawi. Akibat pelapukan daya kohesi batuan menjadi berkurang dan jika tanah tersebut berada pada suatu lereng, dan akibat gaya gravitasi, maka akan bergerak ke bawah, baik secara perlahan (creeping) ataupun cepat (translational sliding, debris flowing, rock falling). Selanjutnya oleh agen transport (air ataupun angin) tanah tersebut diangkut ke tempat yang lebih jauh sebagai sedimen [1].

\section{B. Wireless Sensor Network}

Wireless sensor networks (WSN), atau biasa disebut wireless sensor and actuator networks (WSAN) adalah sensor automatis yang terdistribusi untuk memantau kondisi fisik lingkungan, seperti: suhu, suara, tekanan, kelembaban, dan lain-lain, serta bekerjasama melewatkan data melalui jaringan ke lokasi titik utama. Dengan tambahan ini, node sensor tidak hanya bertanggung jawab untuk pengumpulan data, tetapi juga untuk analisis jaringan, korelasi, dan fusi data sensor sendiri dan data dari node sensor lainnya. Node sensor berkomunikasi tidak hanya dengan satu sama lain, tetapi juga dengan base station (BS) menggunakan radio nirkabe, yang memungkinkan base station dan node sensor untuk menyebarkan data sensor sebagai pengolahan jarak jauh, visualisasi, analisis, dan sistem penyimpanan. Sebagai contoh, gambar 2 . menggambarkan dua bidang sensor pemantauan dua wilayah geografis yang berbeda dan terhubung ke Internet menggunakan base station.

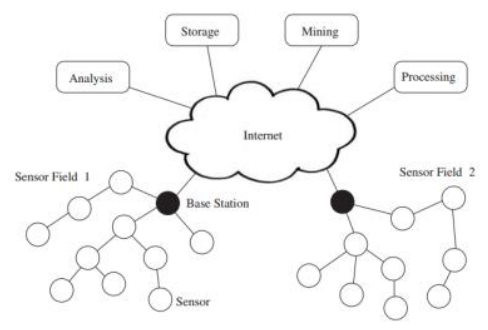

Gbr.2 Wireless Sensor Network

Kemampuan node sensor pad WSN sangat bervariasi. Untuk sensor sederhana, node sensor dapat memantau fenomena fisik tunggal, sedangkan untuk perangkat node sensor yang lebih kompleks menggabungkan banyak teknik penginderaan yang berbeda (misalnya, akustik, optik, magnetik). Node sensor juga dapat berbeda dalam hal kemampuan komunikasi, misalnya menggunakan teknologi ultrasound, inframerah, atau frekuensi radio dengan berbagai kecepatan data dan latency. Sementara sensor sederhana 
hanya dapat mengumpulkan dan mengkomunikasikan informasi tentang lingkungan yang diamati, perangkat yang lebih kuat juga dapat melakukan pengolahan dan pengumpulan fungsi yang luas [5].

\section{Xbee Pro}

Xbee pro adalah modul radio frekuensi (RF) yang berfungsi sebagai transmiter dan receiver. Modul Digi XBee-PRO XSC 900 $\mathrm{MHz}$ memiliki dua kali throughput dan menggunakan arus 20 kali lebih sedikit XSC dibandingkan modul sebelumnya, sehingga ideal untuk aplikasi sensor jarak jauh. Modul $\mathrm{RF}$ ini dilengkapi dengan transceiver ADF7023 dari Analog Devices, sehingga dapat mentransmisikan data sejauh $28 \mathrm{mil}$ Line-of-Sight (LOS) bersamaan dengan konsumsi daya yang rendah.

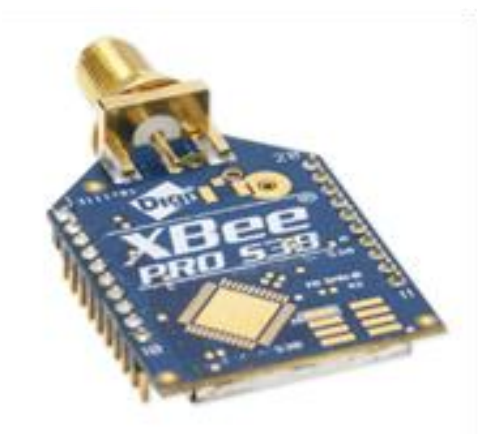

Gbr.3 Modul Xbee Pro S3B

\section{Mikrokontroler}

Mikrokontroller adalah piranti elektronik berupa IC (Integrated Circuit) yang memiliki kemampuan manipulasi data (informasi) berdasarkan suatu urutan instruksi (program) yang dibuat oleh programmer. Mikrokontroler merupakan contoh suatu sistem komputer sederhana yang masuk dalam kategori embedded komputer. Mikrokontroler terdiri dari: CPU (Central Processing Unit), RAM (Random Access Memory), EEPROM/EPROM/PROM/ROM, I/O, Serial \& Parallel, Timer, dan Interupt Controller. Mikrokontroler yang digunakan dalam penelitian ini seri AVR.

\section{E. Sensor}

Akselerometer adalah sebuah perangkat yang digunakan untuk mengukur akselerasi tepat. Akselerasi tepat tidak sama dengan koordinat akselerasi (laju perubahan kecepatan). Sebagai contoh, akselerometer saat diam di permukaan bumi akan mengukur percepatan gravitasi bumi, lurus $\mathrm{ke}$ atas $\mathrm{g} \approx 9,81 \mathrm{~m} / \mathrm{s} 2$. Akselerometer dengan model multiple-axis tersedia untuk mendeteksi besar dan arah percepatan dengan tepat. Karena membentuk vektor, sehingga dapat digunakan untuk mendeteksi perubahan orientasi, mengkoordinasikan percepatan, getaran, dan goncangan.

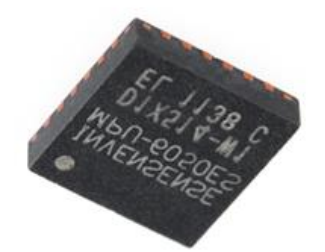

Gbr.4 MPU6050 Accelerometer 3-Axis dan Gyroscope

\section{METODOLOGI PENELITIAN}

\section{A. Perancangan Sensor}

Accelerometer dan Gyroscope MPU6050 digunakan sebagai sensor kemiringan tanah dan getaran. Untuk objek yang statis percepatan yang terukur adalah percepatan gravitasi atau $1 \mathrm{~g}$. Luaran dari akselerometer merupakan fungsi sinus, sehingga kita tidak dapat secara langsung merepresentasikan besaran sudut dari garvitasi. Untuk pengukuran sudut yang akurat digunakan akselerometer 3-axis. Sudut axis $\mathrm{x}$ dan axis $\mathrm{y}$ dapat dihitung menggunakan rumus,

$$
\begin{aligned}
& A x=\arctan \left(\frac{X}{\sqrt{Y^{2}+Z^{2}}}\right) \\
& A y=\arctan \left(\frac{Y}{\sqrt{X^{2}+Z^{2}}}\right)
\end{aligned}
$$

Sebagai pendeteksi getaran semua axis $\mathrm{x}, \mathrm{y}, \mathrm{z}$ pada accelerometer dan gyroscope diaktifkan, sehingga jika terdapat perubahan posisi sudut secara kontinyu, maka prosesor menganggap terjadi sebuah getaran. 


\section{B. Perancangan Node Sensor Network}

Node sensor network memerlukan komponen elektronik berupa mikrokontroler, memori, transceiver, sensor gryroscope, sensor accelometer, dan power source. Node sensor tersebut memiliki fungsi untuk membaca data-data pada objek yang dipantau, menyimpan data dan mengirimkan data secara nirkabel. Gambar 5 memperlihatkan arsitektur dari node sensor yang akan digunakan.

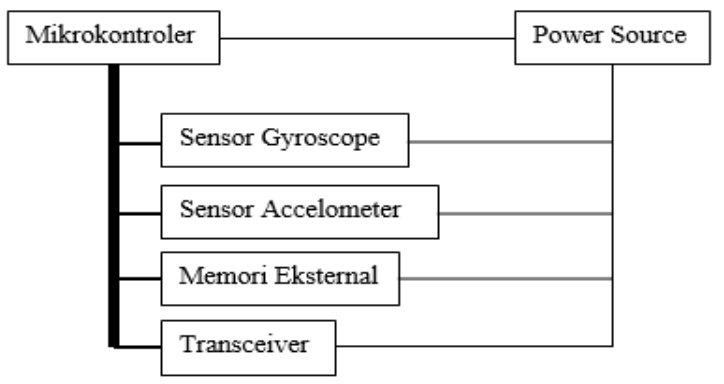

Gbr.5 Arsitektur Sensor node

Arsitektur sensor node terdiri dari:

- Sensor terdiri dari sensor gyroscope dan sensor accelometer.

- Memori diperlukan untuk menyimpan data yang telah didapatkan oleh sensor. Pada dasarnya sebuah mikrokontroler sudah memiliki memori sensiri, namun apabila memori pada mikrokontroler tidak cukup maka dapat menambahkan memori ekstrenal.

- Transceiver berfungsi untuk menerima dan mengirimkan data secara nirkabel menggunakan Xbee.

- Power source berfungsi sebagai sumber energi untuk mengaktifkan perangkat elektronik.

Sensor node network ditempatkan pada lokasi yang memiliki kemungkinan besar terjadi longsor, karena sensor node diletakkan pada tempat yang rawan longsor maka perlu diperhatikan peletakan sensorsensor yang digunakan agar tidak salah dalam pengambilan data.

Selain itu, baterai yang digunakan untuk mengaktifkan komponen elektonik juga diperhatikan.
Pada implementasinya node sensor network menggunakan baterai yang memiliki kapasistas yang besar sehingga tidak terlalu sering mengganti baterai.

\section{Perancangan Model}

Sistem WSN peringatan dini longsor terdiri dari node sensor network dan base station (gambar 6). Node sensor network berfungsi sebagai titik sensor yang mendeteksi parameter getaran, pergerakan tanah, dan kemiringan tanah. Selain itu node sensor network juga mentransmisikan data-data yang didapat dari sensor dan dari node lain ke node sensor pusat atau base station. Base station adalah node sensor network yang bertugas selain menganalisi data dari sensor node, juga menerima data dari nodenode sensor lain yang kemudian di transmisikan ke server pusat.

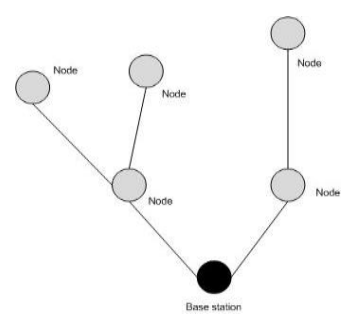

Gbr.6 WSN

Perancangan software pada Node Sensor Network berdasarkan diagram alir (flowchart) berikut:

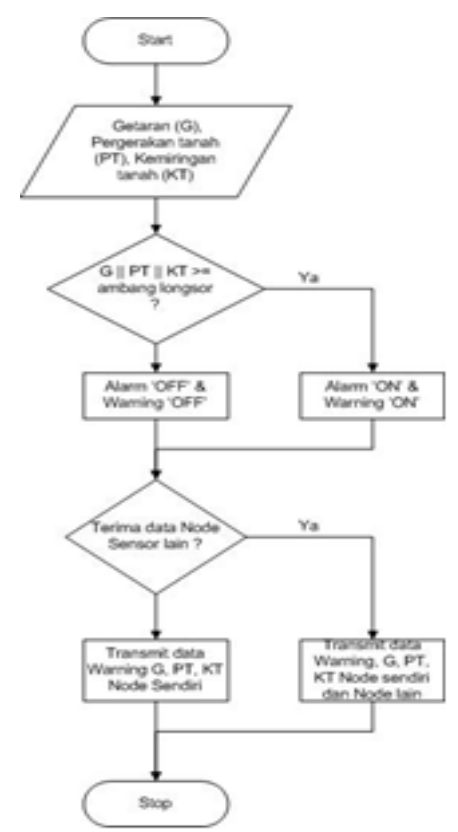

Gbr.7 Flowchart node sensor network 
Node sensor network akan menerima data getaran, pergerakan tanah, dan kemiringan tanah dari sensor-sensor yang tertanam. Mikroprosesor akan mengolah data tersebut dan mengambil keputusan apakah dari parameter tersebut menhgindikasikan akan terjadinya longsor? Jika kondisi terpenuhi, maka node sensor akan menyalakan alarm dan variable warning akan set. Jika tidak, maka alarm dan variable warning akan 'OFF'. Proses selanjutnya, prosesor akan mengambil instruksi apakah ada data dari node sensor lain. Jika ada, maka data warning, getaran, pergeseran tanah, dan kemiringan tanah ditransmisikan bersamaan dengan data dari node lainnya. Jika tidak, maka node sensor hanya mentransmisikan data sensor nya sendiri. Perancangan software pada Base Station berdasarkan diagram alir (flowchart) berikut:

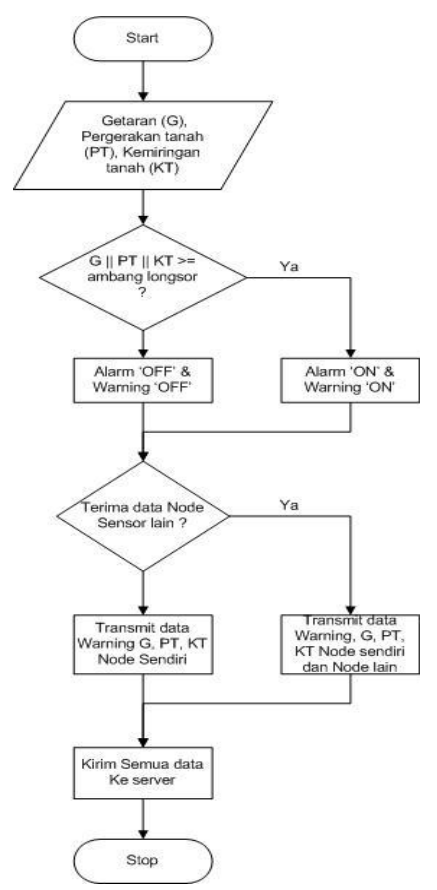

Gbr.8 Flowchart Base Station

Pada dasarnya proses pada base station hampir sama dengan proses node sensor network. Pada base station terdapat proses tambahan yaitu, ketika semua data dari node sensor network sudah terkumpul pada base station proses selanjutnya yang dilakukan adalah mentransmisikan seluruh data node sensor ke server yang telah ditentukan.

\section{IMPLEMENTASI SISTEM}

\section{A. Pengujian MPU6050 (Deteksi Kemiringan Lahan) \\ Berikut merupakan table hasil pengujian sensor MPU6050:}

Tabel 1. Pengujian Sensor MPU6050

\begin{tabular}{|l|l|l|l|}
\hline No. & Sudut Acuan & Axis X sensor & Axis Y sensor \\
\hline 1 & $\begin{array}{l}\mathrm{X}=0^{\circ} \\
\mathrm{Y}=0^{\circ}\end{array}$ & $0.20^{\circ}$ & $0.76^{0}$ \\
\hline 2 & $\begin{array}{l}\mathrm{X}=90^{\circ} \\
\mathrm{Y}=0^{\circ}\end{array}$ & $87.04^{0}$ & $2.97^{0}$ \\
\hline 3 & $\begin{array}{l}\mathrm{X}=0^{0} \\
\mathrm{Y}=90^{\circ}\end{array}$ & $2.49^{\circ}$ & $88.48^{0}$ \\
\hline
\end{tabular}

Dari hasil pengujian Accelerometer dan gyroscope MPU6050 yang digunakan sebagai sensor pendeteksi kemiringan lahan ketika terjadi longsor, terlihat bahwa sensor sudah dapat mendeteksi peubahan sudut pada axis $\mathrm{X}$ dan $\mathrm{Y}$. Namun perlu dilakukan kalibrasi lebih lanjut untuk mendapatkan sudut yang baik. Pada table 1 , terlihat ketika masing-masing axis $\mathrm{X}$ dan $\mathrm{Y}$ dibentuk sudut $90^{\circ}$ hasil luaran sensor tidak $90^{\circ}$, pada axis X $87.04^{\circ}$ dan pada axis Y $88.48^{\circ}$.

\section{B. Komunikasi Data antar node sensor}

Pengambilan data dilakukan dengan mengirimkan data sensor MPU6050 (sensor kemiringan lahan) tiap node (node 1 dan node 2) ke koordinator (base station) melalui jaringan nirkabel. Dari pengujian komunikasi terlihat bahwa node sensor network mampu mengirimkan data ke koordinator (base station). Koordinator (base station) menerima data secara bergantian dari node 1 dan node 2 . Sensor node 1 dan 2 diletakkan pada kemiringan axis $\mathrm{X} 90^{\circ}$ dan axis $\mathrm{Y}$ $0^{\circ}$ (Gambar 9).

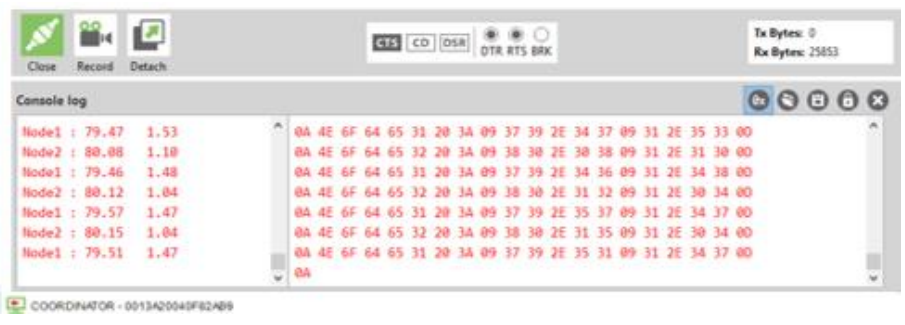

Gbr.9 Log koordinator (base station) menerima data dari node 1 dan 2 


\section{Pengujian Sistem}

Dari keseluruhan sistem, penelitian yang telah dilakukan terbatas pada perancangan

Tabel 2. Data pengujian sistem

\begin{tabular}{|c|c|c|c|}
\hline No & $\begin{array}{l}\text { Fungsi } \\
\text { Sistem }\end{array}$ & Hasil Pengujian & Ket \\
\hline 1 & $\begin{array}{l}\text { Node sensor } \\
\text { medeteksi } \\
\text { longsor }\end{array}$ & $\begin{array}{l}\text { Node sensor dapat } \\
\text { mendeteksi } \\
\text { getaran (axis z } \\
\text { accelerometer dan } \\
\text { gyro) dan } \\
\text { kemiringandengan } \\
\text { range }-90^{\circ}-90^{\circ}\end{array}$ & Berhasil \\
\hline 2 & $\begin{array}{l}\text { Node sensor } \\
\text { memberikan } \\
\text { peringatan } \\
\text { dini longsor }\end{array}$ & $\begin{array}{ll}\text { Node } & \text { sensor } \\
\text { mengaktifkan } \\
\text { alarm dan status } \\
\text { longsor ketika } \\
\text { kemiringan sensor } \\
-45^{\circ} \text { dan } 45^{\circ} \text {. }\end{array}$ & Berhasil \\
\hline 3 & $\begin{array}{l}\text { Node sensor } \\
\log \text { data } \\
\text { internal. }\end{array}$ & $\begin{array}{l}\text { Node sensor dapat } \\
\text { menyimpan data } \\
\text { pada SD card } \\
\text { internal }\end{array}$ & Berhasil \\
\hline 4 & $\begin{array}{l}\text { Jarak } \\
\text { komunikasi } \\
\text { node sensor }\end{array}$ & +- 40 meter & $\begin{array}{l}\text { Berhasil } \\
\text { dengan } \\
\text { catatan }\end{array}$ \\
\hline 5 & \begin{tabular}{lr}
\multicolumn{2}{l}{ Komunikasi } \\
antar & node \\
dan & base \\
station &
\end{tabular} & $\begin{array}{l}\text { Mengirimkan data } \\
\text { status, kemiringan } \\
\text { lahan, dan getaran } \\
\text { ke node lain dan } \\
\text { atau ke base } \\
\text { station }\end{array}$ & Berhasil \\
\hline
\end{tabular}

\section{KESIMPULAN}

Telah dilakukan penelitian mengenai rancang bangun wireless sensor network peringatan dini longsor berbasis mikrokontroler. Berdasarkan data implementasi WSN sudah dapat berkomunikasi antara node sensor dengan komunikator. Data yang dikirimkan berupa data sensor kemiringan lahan. WSN sudah dapat menandakan keadaan bahaya ketika kemiringan diatas $45^{\circ}$ dengan membunyikan alarm. Terdapat beberapa kendala yang dihadapi berupa: belum terdapat sensor yang mendeteksi getaran, belum terdapat sensor yang mampu menghitung seberapa jauh pergeseran tanah, dan jarak antar node yang terbatas maksimum sekitar $40 \mathrm{~m}$. sensor kemiringan lahan dengan sensor gyroscope dan accelerometer, memory eksternal sebagai tempat penyimpan data dan komunikasi data

\section{REFERENSI}

[1] Abbott, P. L., Natural Disaster Fourth Edition. McGraw Hill, 2004.

[2] Djamal, M., Sensor Magnetik Fluxgate Karakteristik dan Aplikasinya, Jurnal Sains Materi Indonesia, 2007.

[3] Geomagz, Vol. 4 No. 4, Desember 2014.

[4] Prawiradisastra, S., Identifikasi Daerah Rawan Bencana Tanah Longsor di Provinsi Lampung. Jurnal Sains dan Teknologi Indonesia Vol. 15, No. 1, April 2013 Hlm.52-59.

[5] Shen, X., Pan, Y., Fundamentals of Wireless Sensor Networks, John Wiley \& Sons Ltd, 2010. 